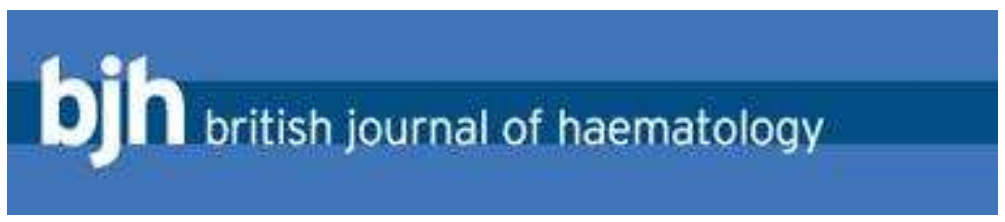

\title{
Assessment of metabolic activity by PET-CT with F-18-FDG in patients with T-cell lymphoma
}

\begin{tabular}{|c|c|}
\hline Journal: & British Journal of Haematology \\
\hline Manuscript ID: & BJH-2010-00712.R1 \\
\hline Manuscript Type: & Ordinary Papers \\
\hline $\begin{array}{r}\text { Date Submitted by the } \\
\text { Author: }\end{array}$ & 14-Jun-2010 \\
\hline Complete List of Authors: & $\begin{array}{l}\text { Storto, Giovanni; IRCCS CROB, Nuclear Medicine } \\
\text { Di Giorgio, Eugenio; Instituto di Biostrutture e Bioimmagini, } \\
\text { Consiglio Nazionale delle Ricerche (CNR), Nuclear Medicine } \\
\text { De Renzo, Amalia; Università "Federico II", Dipartimento di } \\
\text { Biochimica e Biotecnologie Mediche } \\
\text { Micol, Laura; Fondazione Istituto di Diagnostica Nucleare (SDN), } \\
\text { Radiology } \\
\text { Cerciello, Giuseppe; Università "Federico II", Dipartimento di } \\
\text { Biochimica e Biotecnologie Mediche } \\
\text { Nardelli, Anna; Instituto di Biostrutture e Bioimmagini, Consiglio } \\
\text { Nazionale delle Ricerche (CNR), Nuclear Medicine } \\
\text { Capacchione, Daniela; IRCCS CROB, Nuclear Medicine } \\
\text { Castaldi, Elena; Instituto di Biostrutture e Bioimmagini, Consiglio } \\
\text { Nazionale delle Ricerche (CNR), Nuclear Medicine } \\
\text { Ortosecco, Giovanni; Instituto di Biostrutture e Bioimmagini, } \\
\text { Consiglio Nazionale delle Ricerche (CNR), Nuclear Medicine } \\
\text { pace, leonardo; università Federico II, Radiology }\end{array}$ \\
\hline Key Words: & IMAGING, T-CELL LYMPHOMA, NON-HODGKIN-S LYMPHOMA, PET \\
\hline
\end{tabular}

\section{S ScholaroNE




\section{Assessment of metabolic activity by PET-CT with F-18-FDG in patients with T-cell lymphoma}

Giovanni Storto ${ }^{1}$, Eugenio Di Giorgio ${ }^{2}$, Amalia De Renzo $^{3}$, Laura Micol $^{4}$, Giuseppe Cerciello ${ }^{3}$, Anna Nardelli $^{2}$, Daniela Capacchione ${ }^{1}$, Elena Castaldi ${ }^{2}$, Giovanni Ortosecco $^{2}$, and Leonardo Pace C $^{4,5}$

${ }^{1}$ Istituto di Ricovero e Cura a Carattere Scientifico (IRCCS), Centro di Riferimento Oncologico di Basilicata (CROB), Rionero in Vulture, Italy; ${ }^{2}$ Instituto di Biostrutture e Bioimmagini, Consiglio Nazionale delle Ricerche (CNR), Naples, Italy; ${ }^{3}$ Dipartimento di Biochimica e Biotecnologie Mediche, Università "Federico II", Naples, Italy; ${ }^{4}$ Istituto di Ricerca e Cura a Carattere Scientifico (IRCCS), Fondazione Istituto di Diagnostica Nucleare (SDN), Naples, Italy; ${ }^{5}$ Dipartimento di Scienze Biomorfologiche e Funzionali, Università "Federico II", Naples, Italy

\section{Reprint requests and correspondence:}

Giovanni Storto, Istituto di Ricovero e Cura a Carattere Scientifico (IRCCS), Centro di Riferimento Oncologico di Basilicata (CROB), Via P. Pio 1, 85028 Rionero in Vulture, Italy

Phone: +39 0972-726560 - Fax: +390972-726399 - E-mail: giosto24@ hotmail.com

Dedication: the article is dedicated to Mr. Prof. Bruno Rotoli which was an irreplaceable teacher for our work 


\section{SUMMARY}

${ }^{18}$ F-fluorodeoxyglucose positron emission tomography (PET/CT) is highly sensitive for the imaging of B-cell lymphomas; its usefulness in T-cell lymphomas (TL) is less defined. We retrospectively evaluated the metabolic activity in TL patients scheduled to receive chemotherapy. Methods: 20 consecutive patients with TL underwent PET/CT and the results were correlated to Ki67 and compared with those from indolent B-NHL and extranodal aggressive B-NHL. Results: Mean Ki-67 was $64 \% \pm 15 \%$ in TL. (On a patient basis,) No relationship between individual mean SUVmax and Ki-67 values was observed $(r=0.1 ; \mathrm{p}=0.6)$. The mean SUVmax in TL was lower as compared to both indolent and extranodal aggressive B-NHL $(6.1 \pm 4$ vs $9.1 \pm 6$ and $8.9 \pm 5$, respectively; $\mathrm{p}<0.01$ ). Within extra-nodal locations the TL still presented values lower than the other groups $(5.3 \pm 3$ vs $9.5 \pm 6$ and $8.9 \pm 5$, respectively; $\mathrm{p}<0.05)$. Nodal SUVmax of TL was lower than nodal indolent B-NHL (6.4 \pm 3 vs $8.8 \pm 6 ; \mathrm{p}<0.05)$. Conclusion: Although clinically aggressive and high Ki-67 values, TL have a low metabolic activity at PET/CT. TL patients had an uptake index lower than patients presenting indolent or extranodal aggressive B-NHL.

Keywords: T-cell lymphomas; FDG; metabolic activity; standard uptake value; positron emission tomography 


\section{INTRODUCTION}

T-cell lymphomas (TL) comprise a heterogeneous group of uncommon diseases accounting for approximately 10-15\% of all non-Hodgkin's lymphomas. Compared to B-cell lymphomas, TL more frequently involve extranodal sites and have a worse prognosis. The staging of patients with malignant lymphoma take account of physical examination, instrumental procedures and results from peripheral blood and bone marrow involvement, if any. Recently, ${ }^{18}$ F-fluorodeoxyglucose positron emission tomography-computed tomography (PET/CT) has been widely recognized as a suitable diagnostic tool in staging (Jerusalem et al, 2001a), follow-up and tumour response assessment of lymphoma patients (Mikhaeel et al, 2000; Naumann et al, 2004; Zinzani et al, 2004; Castellucci et al, 2005); its prognostic role has been evoked (Jerusalem et al, 1999; Mikhaeel et al, 2005; Haioun et al, 2005; Cheson et al, 2007). PET/CT offers the advantage of functional tissue characterization, which is mostly independent from morphologic criteria assessing the extent of the disease; it has higher sensitivity than conventional anatomic imaging modalities thus often redirecting patient management. Different ${ }^{18}$ F-fluorodeoxyglucose (FDG) uptake among different subtypes of lymphoma has been reported (Schoder et al, 2005; Wong et al, 2005; Tsukamoto et al, 2007), which could be explained by the complex histological profile including the proliferating capacity of tumour cells, the proportion of viable tumour cells and the presence of reactive non-malignant cells (Kubota et al, 1993). The evidence that the degree of FDG accumulation correlates well with the percentage of proliferative cells in the biopsied samples rather than with the histologic grade has been reported mainly in B-cell non-Hodgkin's lymphomas (Laskinen-Kallio et al, 1991). Conversely, only few data have pointed about the amount of tracer uptake and the role of PET/CT in staging T-cell neoplasms which usually exhibit aggressive clinical behaviour (Kako et al, 2007; Karantanis et al, 2008; Khong et al, 2008; Tang et al, 2009). Accordingly, we evaluated the results from the semiquantitative assessment of a staging PET/CT in patients with histologically proven T-cell 
lymphoma, comparing the findings to $\mathrm{Ki}-67$ proliferation index and to those obtained in patients presenting indolent- or aggressive B-cell non-Hodgkin lymphoma. This imaging modality might have a role for tailoring therapy in such setting redirecting to alternative drugs or new combination treatment algorithms on a metabolic assessment basis. DESIGN AND METHODS

\section{Patients}

Twenty patients $(7$ women; $54.9 \pm 16.5$ y) [Table 1] with histologically proven T-cell lymphoma underwent baseline PET/CT scan 2-3 weeks prior to start a first line therapy. All patients underwent neck echography, chest, abdomen and pelvis CT and bone marrow biopsy. Diagnoses were made according to the WHO classification. Number and dimensions of involved nodal and extra-nodal sites (regions) were evaluated at PET/CT (as per patient tumoral burden). Results of PET/CT scans obtained from 20 patients ( 7 women; $53.6 \pm 13.9$ y) with indolent B-NHL and 20 patients ( 7 women; $54.1 \pm 14.5$ y) presenting extra-nodal aggressive B-NHL served as control. All patients signed informed consent in accordance with the Declaration of Helsinki.

\section{Immunohistochemical staining}

Ki-67-stained sections of tissue specimens from cases of T-cell lymphoma were available to determine the distribution of proliferating cells and proliferation rate of cells. A monoclonal mouse anti-human ki-67 antigen, clone MIB-1 (Dakocytomation, Danmark) was used. Ki-67 staining was assessed by subjectively evaluating the percentage of positive cells.

\section{Imaging modalities}

PET and CT were carried out with a commercial combined PET/CT scanner (Discovery LS; GE Milwaukee, WI, USA) combining an Advance NXi PET scanner and a Light Speed Plus four rows 
MDCT system. PET/CT imaging was acquired 75-90 minutes after intravenous administration of 12$15 \mathrm{mCi}$ (444-555 MBq) of FDG. During the 4-6 hours prior to imaging patients were fasting. Blood glucose level was determined in all patients before FDG administration and a cut-off value of less than $(160 \mathrm{mg} / \mathrm{dL}) \mathbf{8 . 8 8} \mathrm{mmol} / \mathrm{L}$ was considered appropriate to perform examination. Helical CT (pitch 1.5; $120 \mathrm{mAs} ; 120 \mathrm{kVp}$ ) was performed without intravenous contrast medium. PET scan was performed with four minutes per bed position and six to eight bed positions per patient, depending on patient height. Raw computed tomography (CT) data were reconstructed into transverse images with a 4.25-mm section thickness. Sagittal and coronal CT images were generated by reconstruction of transverse data.

Raw PET data were reconstructed with and without attenuation correction into transverse, sagittal, and coronal images. Attenuation correction was based on CT attenuation coefficients, which were determined by iterative reconstruction. All images were reviewed at a workstation by using PET/CT fusion software (Volumetrix for PET, GE). Each PET/CT study was interpreted by three experienced observers in consensus; one of them was also a radiologist. The examiners first evaluated the CT images alone. Mass sizes (nodal or extra-nodal) were visually estimated and the most significant was measured at least in maximum diameter by using a vendor-provided software. A lesion in the baseline study was defined as an identifiable mass or lymph node larger than $1 \mathrm{~cm}$ in minimum diameter with soft-tissue/mediastinal window settings. Up to 6 hottest (representative) lesions per patient were considered. Then, maximum standardized uptake values, body weight corrected (SUVmax), were determined by using vendor-provided software on PET scans, according to the European Organization for Research and Treatment of Cancer's (EORTC) PET recommendations (Young et al, 1999) and to recent upgraded guidelines (Cheson et al, 2007; Juweid et al, 2007). Briefly, focal or diffuse FDG uptake above background in a location mismatched with normal anatomy or physiology was interpreted as abnormal and was considered to be (evocative) indicative of a lymphoma lesion. The 
result of PET/CT was considered positive if PET/CT detected a lymphoma lesion in at least one site detected by CT series or by physical examination.

\section{Statistical analysis}

Data are expressed as proportions or as means \pm 1 standard deviations, as appropriate. One-way ANOVA was used for comparing means between groups. Post hoc analysis with Bonferroni correction was performed. Differences between mean values were assessed by Student's $t$ test (twotailed probability) for unpaired data. Linear regression analysis was used to assess the relationship between mean SUVmax and Ki-67 values, on a patient basis. A probability $(p)$ value $<0.05$ was considered significant.

\section{RESULTS}

Patient characteristics of each group (study and controls) are summarized in Table 1 according to the prevalence of the histological subtypes. (Mean) The Number of extra-nodal and nodal sites per subtype (are) is also shown. PET/CT scan was positive in all patients of the study and control groups. CT scans performed as a part of PET/CT study allowed to identify extra-nodal and nodal sites in all groups of patients. ; (most representative lesions were measured at least in maximum diameter, those of TL patients are recorded in Table 2)

(Classification of TL patients and controls

According to the WHO classification the histological subtypes of TL patients were: peripheral T-cell lymphoma, unspecified (PTCL-U, $n=9$ ), anaplastic large cell lymphoma (ALCL, $n=6$ ), mycosis fungoides (MF, $n=3)$, extranodal NK/T-cell lymphoma, nasal type $(\mathrm{ENKL}, n=1)$, angioimmunoblastic T-cell lymphoma (AILT, $\boldsymbol{n}=\mathbf{1}$ ). ) Bone marrow biopsy was positive in 11/20 patients with TL. Fourteen patients with TL were classified as having a stage IV disease, three a stage 
III and three a stage II. A total of 12 bone marrow lesions were detected, eight cutaneous/subcutaneous lesions were recorded in MF patients, one in a ALCL patient.

(In the group of indolent NHLs, 18 patients were classified as having follicular lymphoma and two as extranodal marginal zone B-cell lymphoma (EMZL). Among patients with extra-nodal aggressive NHL, 17 had diffuse large B-cell lymphoma, two showed blastic EMZL and one patient had a intravascular large B-cell lymphoma.) In patients with indolent NHL 6/20 had both extra-nodal and nodal sites involved, 8/20 had nodal and 6/20 exclusive extranodal involvement.

\section{Tumor burden and Ki-67 in TL}

Analyzing patient tumour burden, a mean number of $3.8 \pm 2$ and of $4.7 \pm 2$ sites were involved in the group with TL and with indolent B-NHL, respectively $(\mathrm{p}=\mathrm{ns})$ whereas extra-nodal aggressive B-NHL had $1.5 \pm 0.4$ sites involved ( $\mathrm{p}<0.05$ vs TL and vs indolent $\mathrm{B}-\mathrm{NHL})$.

Tissue specimens were collected from 13 nodal locations, 4 cutaneous/subcutaneous lesions, 2 from bone marrow and one from gastric involvement. Mean Ki-67 was $64 \% \pm 15 \%$ in patients with TL (range: $30 \%-80 \%$ ). On a patient basis, No relationship between individual mean SUVmax and Ki-67 values was observed $(r=0.1 ; p=0.6)$.

\section{Semiquantitative assessment in TL patients and controls}

Considering all detected representative lesions, the mean SUVmax in patients with TL was lower as compared to either indolent and extra-nodal high grade B-NHL $(6.1 \pm 4$ vs $9.1 \pm 6$, and vs $8.9 \pm 5$, respectively; $\mathrm{p}<0.01)$ (Figure 1).

When the SUVmax was assessed only just in the extra-nodal locations, the TL group still presented lower values than the other groups $(5.3 \pm 3$ vs $9.5 \pm 6$ and $8.9 \pm 5$, respectively; $\mathrm{p}<0.05)$ (Figure 2A) (Fig 1A).

Finally, the SUVmax in nodal locations of patients with TL was lower than in nodal indolent 
B-NHL $(6.4 \pm 3$ vs $8.8 \pm 6 ; \quad$ p $<0.05)$ (Figure 2B) (Fig 1B). Within the TL or indolent B-NHL groups there was no difference in SUVmax values between extra-nodal and nodal sites. In TL patients the mean SUVmax of bone marrow lesions was $6.0 \pm 3$, it was not different from that of the other extra-nodal lesions grouped $(5.0 \pm 3 ; \mathrm{p}=\mathrm{ns})$.

No differences were found between SUVmax values of indolent B-NHL and extra-nodal aggressive B-NHL.

\section{DISCUSSION}

In the present study we found that patients with TL had a significant but low metabolic activity at PET scan, regardless of a considerable tumour burden, an aggressive clinical behaviour and high values of Ki-67. These patients had a lower uptake index in the involved regions than patients presenting either indolent or aggressive B-NHL.

(Although several studies have strengthened the value of FDG-PET in the assessment of malignant lymphoma at diagnosis $[1,2,6,18]$, its role in revealing different amount of FDG uptake among various histological subtype of lymphoid malignancies is still under evaluation. $[10,19-23]$ As a result, the histological subtype of malignancy should be carefully considered in assessing PET-FDG results.)

Natural killer (NK)/T-cell lymphomas represent a rare type of lymphoma derived from either activated NK cell or, rarely, cytotoxic T cells. It usually originates in the nasal cavity/nasopharynx and invades the surrounding tissues; a delay in diagnosis could result in a fatal outcome. T-cell neoplasms frequently display aggressive clinical behaviour and a prognosis not as good as B-cell neoplasms,

(Rudiger et al, 2002; Mounier et al, 2004 ) mostly because of the high frequency of advanced-stage disease and extranodal involvement, as a consequence of intrinsic histopathological features. The 
unfavourable prognosis of this tumour emphasizes the need for more effective and useful diagnostic tools in order to implement beneficial therapeutic strategies.

There are only few published data substantiating the use of PET/CT in patients presenting Tcell lymphoma (Kako et al, 2007; Khong et al, 2008; Suh et al, 2008) being it alternatively allotted as a valuable or useless tool in such disease (Karantanis et al, 2008; Khong et al, 2008; Tang et al, 2009). Our data confirm the findings of others who demonstrated a high positive rate of pre-therapeutic PET/CT in most subtypes of T-cell neoplasms, comparable to what observed for B-cell neoplasms (Haioun et al, 2005). All patients enrolled in the present study showed significant amount of tracer uptake at PET-CT scan.

Previous studies have demonstrated a substantial overlap in the intensity of FDG uptake between patients with indolent and aggressive B-cell lymphoma in the low SUV range (Rodriguez et al,1995; Lapela et al, 1995). However, Schoder et al. (2005) reported that the intensity of FDG uptake is generally lower in indolent as compared with aggressive non-Hodgkin's lymphoma and that the likelihood for aggressive disease increases in parallel with increases in SUV. This is not the case of TL, in which mechanisms other than those sustaining aggressiveness should be considered.

In our setting, for instance, mean SUVmax of lesions was constantly low, though significant, either for nodal or extra-nodal involved districts while TL patients showed high values of Ki-67 which is an established marker of cell proliferation.

(Uptake of FDG in lymphoma is influenced by many different biological factors, including molecular, such as oncogene expression as well as patho-physiological aspects such as tumor perfusion, apoptosis and viable cell fraction, effects of hypoxia, amount of inflammatory cell infiltration and lastly by substrate utilization. However,) There are some evidences (Kako et al, 2007; Karantanis et al, 2008) that PET/CT appears to be less sensitive for cutaneous and bone marrow involvement in TL and, in general, for the detection of extranasal sites. On the other hand, 
some authors (Kuo et al, 2008; Berk et al, 2008) have focused on the potential of PET/CT for improving the staging and the monitoring of response to therapy in TL. This was proven for cutaneous, nodal, and visceral disease in cutaneous T-cell lymphoma as well as for detection of subcutaneous nodules in extranodal nasal NK/T-cell lymphomas, highlighting the important role of FDG-PET in the staging of these diseases.

Our setting showed a distinctive involvement of extra-nasal sites, mostly cutaneous, visceral or with bone marrow locations and some patients had nodal concern. All subjects had a significant tumour burden, an aggressive behaviour and a positive scan. Nevertheless, comparing the degree of tracer uptake between extra-nodal and nodal locations of TL patients was not different. (i.e. supposed disparities in blood support), we were not able to detect differences, being it significant but moderate in both districts.) Irrespective of locations involved, mechanisms of metabolic deregulation during the genesis of T-cell lymphomas and cell transformation might be more complex than merely meeting the cellular requirements of growth and proliferation.

Although clear evidence is lacking at this time, biologic differences among specific pathologic subtypes of lymphoma can be evocated in determining different degrees of FDG uptake. For instance, T-cell lymphomas histologically can show a broad cytologic spectrum even if apoptosis and necrosis are common (Cheung et al, 2003), both affecting FDG uptake. Higher activity of glucose-6phosphatase might determine a lower FDG uptake as in some histological subtypes of Hodgkin's disease (Reed-Sternberg and Hodgkin cells) and in hepatocellular carcinoma (Pangalis \& Tsavaris, 1986; Torizuka et al, 1995). There is the evidence that some TL cells mirror, histo-pathologically, the mononuclear cells or even the typical Sternberg-Reed cells of Hodgkin's disease (Whitcomb et al, 1983). Finally, it should be considered the expression of membrane glucose transporters, Glut-1 (Aloj et al, 1999) or the role of lectins, a group of specific membrane proteins that preferentially bind to carbohydrates inside and outside the cells, playing a critical function in cancer biology and in various 
lymphoma subtypes as well (Raz et al, 1986; Monsigny et al, 1988; Gabius et al, 1989; Nakahara \& Raz, 2008).

Taking into account the above mentioned issues, we aimed to compare FDG avidity of extra-nodal and nodal locations of TL patients with that detected in both extra-nodal and nodal locations of sex- and age matched patients presenting indolent B-NHL. Patients with TL showed lower FDG uptake in both nodal and extra-nodal locations as compared to those of indolent B-NHL. Recent data in indolent lowgrade lymphomas (follicular and marginal zone lymphomas) (showed) have shown positive FDG uptake despite a low tumour cell proliferation (Hoffmann et al, 2003; Elstrom et al, 2003; Jerusalem et al, 2001b; Najjar et al, 2001), (detecting metabolic activity in both follicular and marginal zone lymphomas $[42,43])$. The fact that follicular lymphomas almost invariably showed high FDG uptake demonstrates that the histologic grading is not the most important predictor for FDG avidity (Elstrom et al, 2003).

SUV values obtained at extra-nodal level in TL were compared with those of sex- and age matched patients having extra-nodal aggressive lymphoma; once more the degree of FDG uptake in TL was significantly lower, confirming that reasons other than aggressiveness are implicated in cellular tracer accumulation.

Although there still may be considerable overlap between SUVs of benign tissue and those of malignant tissue, we quantified the intensity of FDG activity using a SUV cut-off of around 2.5 to 3.0 which has been indicated evocative of malignant involvement (Lucignani et al, 2004).

Our findings suggest a careful quantitative evaluation of FDG PET images in such disease as not always the higher the proliferation the higher the metabolic activity.

(To our knowledge this is the first study comparing the degree of FDG uptake in TL with matched both indolent or aggressive B-NHL. Comparisons with other published studies are 
difficult, since most data are derived from solid tumours and nodal-based lymphomas, and no previous studies have been published comparing SUVs in TL and B-NHL.)

The (As) accurate staging of TL is essential for providing the patient with appropriate prognostic information and for guiding the clinician in selecting the treatment option according to the tumour metabolic activity which seems not directly related to the proliferation. As a result, alternative drugs such as receptor-selective, immune- modulating or apoptosis-inducing agents rather than those disrupting cancer growth by direct cytotoxic effect could be preferred (see targeted therapy).

The analysis of additional patients will provide further information for FDG-PET impact on the management of such disease. In addition, the comprehension of the exact cellular mechanisms sustaining different metabolic profiles in various lymphomas will be of crucial value.

\section{AUTHORSHIP AND DISCLOSURES}

The authors have indicated they have no financial conflicts of interest.

All co-authors have reviewed this paper and approve of its publication. In particular, G.S. designed the research, cared for research subjects, collected data, analyzed data, conceived, wrote and reviewed the manuscript. E.D.G., A.D.R., L.M. and G.C. cared for research subjects and reviewed the manuscript. A.N., D.C., E.C., and G.O. collected, analyzed data and reviewed the manuscript. A.N. and E.C. performed radiochemistry procedures, analyzed data and reviewed the manuscript. B.R. and L.P. reviewed the manuscript.

\section{RUNNING HEADS}

Assessment of metabolic activity in T-cell lymphoma 


\section{REFERENCES}

Aloj, L., Caraco, C., Jagoda, E., Eckelman, W.C. \& Neumann, R.D. (1999) Glut-1 and hexokinase expression: relationship with 2-fluoro-2-deoxy-D-glucose uptake in A431 and T47D cells in culture. Cancer Research, 59, 4709-4714. (Armitage, J.O. (2005) Staging non-Hodgkin lymphoma. CA A Cancer Journal for Clinicians, 55,368-376.)

Berk, V., Yildiz, R., Akdemir, U.O., Akyurek, N., Karabacak, N.I., Coskun, U. \& Benekli, M. (2008) Disseminated extranodal NK/T-cell lymphoma, nasal type, with multiple subcutaneous nodules: utility of 18F-FDG PET in staging. Clinical Nuclear Medicine, 33, 365-366.

Castellucci, P., Nanni, C., Farsad, M., Alinari, L., Zinzani, P., Stefoni, V., Battista, G., Valentini, D., Pettinato, C., Marengo, M., Boschi, S., Canini, R., Baccarani, M., Monetti, N., Franchi, R., Rampin, L., Fanti, S. \& Rubello D. (2005) Potential pitfalls of 18F-FDG PET in a large series of patients treated for malignant lymphoma: prevalence and scan interpretation. Nuclear Medicine Communications, 26, 689-694.

Cheson, B.D., Pfistner, B., Juweid, M.E., Gascoyne, R.D., Specht, L., Horning, S.J., Coiffier, B., Fisher, R.I., Hagenbeek, A., Zucca, E., Rosen, S.T., Stroobants, S., Lister, T.A., Hoppe, R.T., Dreyling, M., Tobinai, K., Vose, J.M., Connors, J.M., Federico, M. \& Diehl, V. (2007) The International Harmonization Project on Lymphoma Revised response criteria for malignant lymphoma. Journal of Clinical Oncology, 25, 579-586.

Cheung, M.M., Chan, J.K. \& Wong, K.F. (2003) Natural killer cell neoplasms: a distinctive group of highly aggressive lymphomas/leukemias. Seminars in Hematology, 40, 221-232.

Elstrom, R., Guan, L., Baker, G., Nakhoda, K., Vergilio, J.A., Zhuang, H., Pitsilos, S., Bagg, A., Downs, L., Mehrotra, A., Kim, S., Alavi, A. \& Schuster, S.J. (2003) Utility of FDG-PET scanning in lymphoma by WHO classification. Blood, 101, $3875-3876$.

Gabius, S., Hellmann, K.P., Ciesiolka, T., Nagel, G.A. \& Gabius, H.J. (1989) Lineage- and differentiation-dependent alterations in the expression of receptors for glycoconjugates (lectins) in different human hematopoietic cell lines and low grade lymphomas Blut, 59, 165-170.

Haioun, C., Itti, E., Rahmouni, A., Brice, P., Rain, J.D., Belhadj, K., Gaulard, P., Garderet, L., Lepage, E., Reyes, F. \& Meignan M. (2005) [18F]fluoro-2-deoxy-D-glucose positron emission tomography (FDG-PET) in aggressive lymphoma: an early prognostic tool for predicting patient outcome. Blood, 106,1376-1381.

(Hoffmann, M., Kletter, K., Diemling, M., Becherer, A., Pfeffel, F., Petkov, V., Chott, A. \& Raderer, M. (1999) Positron emission tomography with fluorine-18-2-fluoro-2-deoxy-D-glucose (F18-FDG) does not visualize extranodal 
Hoffmann, M., Kletter, K., Becherer, A., Jäger, U., Chott, A. \& Raderer, M. (2003) 18F-Fluorodeoxyglucose positron emission tomography (18F-FDGPET) for staging and follow-up of marginal zone B cell lymphoma. Oncology, 64, 336340.

Jerusalem, G., Beguin, Y., Fassotte, M.F., Najjar, F., Paulus, P., Rigo, P. \& Fillet, G. (1999) Whole-body positron emission tomography using 18F-fluorodeoxyglucose for post-treatment evaluation in Hodgkin's disease and non-Hodgkin's lymphoma has higher diagnostic and prognostic value than classical computed tomography scan imaging. Blood, 94, 429433.

Jerusalem, G., Beguin, Y., Fassotte, M.F., Najjar, F., Paulus, P., Rigo, P. \& Fillet, G. (2001) Whole-body positron emission tomography using 18F-fluorodeoxyglucose compared to standard procedures for staging patients with Hodgkin's disease. Haematologica, 86, 266-273.

Jerusalem, G., Beguin, Y., Najjar, F., Hustinx, R., Fassotte, M.F., Rigo, P. \& Fillet, G. (2001) Positron emission tomography (PET) with 18F-fluorodeoxyglucose (18F-FDG) for the staging of low-grade non-Hodgkin's lymphoma (NHL). Annals of Oncology, 12, 825-830.

Juweid, M.E., Stroobants, S., Hoekstra, O.S., Mottaghy, F.M., Dietlein, M., Guermazi, A., Wiseman, G.A., Kostakoglu, L., Scheidhauer, K., Buck, A., Naumann, R., Spaepen, K., Hicks, R.J., Weber, W.A., Reske, S.N., Schwaiger, M., Schwartz, L.H., Zijlstra, J.M., Siegel, B.A. \& Cheson, B.D. (2007) Use of positron emission tomography for response assessment of lymphoma: consensus of the Imaging Subcommittee of International Harmonization Project in Lymphoma. Journal of Clinical Oncology, 25, 571-578.

Kako, S., Izutsu, K., Ota, Y., Minatani, Y., Sugaya, M., Momose, T., Ohtomo, K., Kanda, Y., Chiba, S., Motokura, T. \& Kurokawa, M. (2007) FDG-PET in T-cell and NK-cell neoplasms. Annals of Oncology, 18, 1685-1690.

Karantanis, D., Subramaniam, R.M., Peller, P.J., Lowe, V.J., Durski, J.M., Collins, D.A., Georgiou, E., Ansell, S.M. \& Wiseman, G.A. (2008) The value of [(18)F]fluorodeoxyglucose positron emission tomography/computed tomography in extranodal natural killer/T-cell lymphoma. Clinical Lymphoma \& Myeloma, 8,94-99.

Khong, P.L., Pang, C.B., Liang, R., Kwong, Y.L. \& Au, W.Y. (2008) Fluorine-18 fluorodeoxyglucose positron emission tomography in mature T-cell and natural killer cell malignancies. Annals of Haematology, 87, 613-621s.

(Kostakoglu, L., Leonard, J.P., Coleman, M. \& Goldsmith, S.J. (2004) The role of FDG-PET imaging in the management of lymphoma. Clinical Advances in Hematology and Oncology, 2, 115-121.)

Kubota, K., Kubota, R. \& Yamada, S. (1993) FDG accumulation in tumor tissue. The Journal of Nuclear Medicine, 34, 
419-421.

Kuo, P.H., McClennan, B.L., Carlson, K., Wilson, L.D., Edelson, R.L., Heald, P.W. \& Girardi, M. (2008) FDG-PET/CT in the evaluation of cutaneous T-cell lymphoma. Molecular Imaging and Biology, 10, 74-81.

Lapela, M., Leskinen, S., Minn, H.R., Lindholm, P., Klemi, P.J., Söderström, K.O., Bergman, J., Haaparanta, M., Ruotsalainen, U., Solin, O., Joensuu, H. (1995) Increased glucose metabolism in untreated non-Hodgkin's lymphoma: A study with positron emission tomography and fluorine-18-fluorodeoxyglucose. Blood, 86, 3522-3527.

Leskinen-Kallio, S., Ruotsalainen, U., Någren, K., Teräs, M. \& Joensuu, H. (1991) Uptake of carbon-11-methionine and fluorodeoxyglucose in non-Hodgkin's lymphoma: a PET study. The Journal of Nuclear Medicine, 32, 1211-1218.

Lucignani, G., Paganelli, G. \& Bombardieri, E. (2004) The use of standardized uptake values for assessing FDG uptake with PET in oncology: a clinical perspective. Nuclear Medicine Communications, 25, 651-656.

Mikhaeel, N.G., Timothy, A.R., O'Doherty, M.J., Hain, S. \& Maisey M.N. (2000) 18-FDG-PET as a prognostic indicator in the treatment of aggressive non-Hodgkin's lymphoma — comparison with CT. Leukemia and Lymphoma, 39, 543-553.

Mikhaeel, N.G., Hutchings, M., Fields, P.A., O'Doherty, M.J. \& Timothy, A.R. (2005) FDG-PET after two to three cycles of chemotherapy predicts progression-free and overall survival in high-grade non-Hodgkin lymphoma. Annals of Oncology, 16, 1514-1523.

Monsigny, M., Roche, A.C., Kieda, C., Midoux, P. \& Obrénovitch, A. (1988) Characterization and biological implications of membrane lectins in tumor, lymphoid and myeloid cells. Biochimie, 70, 1633-1649.

Mounier, N., Gisselbrecht, C., Briere, J., Haioun, C., Feugier, P., Offner, F., Recher, C., Stamatoullas, A., Morschhauser, F., Macro, M., Thieblemont, C., Sonet, A., Fabiani, B. \& Reyes, F. (2004) All aggressive lymphoma subtypes do not share similar outcome after front-line autotransplantation: a matched-control analysis by the Groupe d'Etude des Lymphomes de l'Adulte (GELA). Annals of Oncology, 15,1790-1797.

Najjar, F., Hustinx, G., Jerusalem, G., Fillet, G. \& Rigo, P. (2001) Positron Emission Tomography (PET) for staging lowgrade non-Hodgkin's lymphomas (NHL). Cancer Biotherapy and Radiopharmaceuticals, 16, 297-304.

Nakahara, S. \& Raz, A. (2008) Biological modulation by lectins and their ligands in tumor progression and metastasis. Anti-Cancer Agents in Medicinal Chemistry, 8, 22-36.

Naumann, R., Beuthien-Baumann, B., Reiss, A., Schulze, J., Hänel, A., Bredow, J., Kühnel, G., Kropp, J., Hänel, M., Laniado, M., Kotzerke, J. \& Ehninger, G. (2004) Substantial impact of FDG PET imaging on the therapy decision in patients with early-stage Hodgkin's lymphoma. British Journal of Cancer, 90, 620-625.

Pangalis, G.A. \& Tsavaris, N.B. (1986) Glucose-6-phosphatase activity of Reed-Sternberg and Hodgkin cells. 
Hematological Oncology, 4, 261-266.

Raz, A., Meromsky, L. \& Lotan, R. (1986) Differential expression of endogenous lectins on the surface of nontumorigenic, tumorigenic, and metastatic cells. Cancer Research, 46, 3667-3672.

Rodriguez, M., Rehn, S., Ahlstrom, H., Sundström, C. \& Glimelius, B. (1995) Predicting malignancy grade with PET in non-Hodgkin's lymphoma. The Journal of Nuclear Medicine, 36, 1790-1796.

Rudiger, T., Weisenburger, D.D., Anderson, J.R., Armitage, J.O., Diebold, J., MacLennan, K.A., Nathwani, B.N., Ullrich, F. \& Müller-Hermelink, H.K. (2002) Peripheral T-cell lymphoma (excluding anaplastic large-cell lymphoma): results from the Non-Hodgkin's Lymphoma Classification Project. Annals of Oncology, 13, 140-149.

Schoder, H., Noy, A., Gonen, M., Weng, L., Green, D., Erdi, Y.E., Larson, S.M. \& Yeung, H.W. (2005) Intensity of 18fluorodeoxyglucose uptake in positron emission tomography distinguishes between indolent and aggressive nonHodgkin's lymphoma. Journal of Clinical Oncology, 23, 4643-4651.

Suh, C., Kang, Y.K., Roh, J.L., Kim, M.R., Kim, J.S., Huh, J., Lee, J.H., Jang, Y.J. \& Lee, B.J. (2008) Prognostic Value of Tumor 18F-FDG Uptake in Patients with Untreated Extranodal Natural Killer/T-Cell Lymphomas of the Head and Neck. The Journal of Nuclear Medicine, 49, 1783-1789.

Tang, B., Douglas-Nikitin, V., Balon, H., Wong, C.O., Khong, P.L. \& Wong, C.Y. (2009) Exceptionally low metabolic activity in aggressive peripheral T-cell lymphoma. Nuclear Medicine Communications, 30, 838-840.

(Tsujikawa, T., Otsuka, H., Morita, N., Saegusa, H., Kobayashi, M., Okazawa, H. \& Nishitani, H. (2008) Does partial volume corrected maximum SUV based on count recovery coefficient in 3D-PET/CT correlate with clinical aggressiveness of non-Hodgkin's lymphoma? Annals of Nuclear Medicine, 22, 23-30.)

Tsukamoto, N., Kojima, M., Hasegawa, M., Oriuchi, N., Matsushima, T., Yokohama, A., Saitoh, T., Handa, H., Endo, K. \& Murakami, H. (2007) The usefulness of (18)F-fluorodeoxyglucose positron emission tomography ((18)F-FDG-PET) and a comparison of (18)F-FDG-pet with (67)gallium scintigraphy in the evaluation of lymphoma: relation to histologic subtypes based on the World Health Organization classification. Cancer, 110, 652-659.

Torizuka, T., Tamaki, N., Inokuma, T., Magata, Y., Sasayama, S., Yonekura, Y., Tanaka, A., Yamaoka, Y., Yamamoto, K. \& Konishi, J. (1995) In vivo assessment of glucose metabolism in hepatocellular carcinoma with FDG-PET. The Journal of Nuclear Medicine, 36, 1811-1817.

Whitcomb, C.C., Olivella, J.E. \& Byrne. G.E. Jr. (1983) T-cell lymphoma-leukemia. Pathologic observations in three cases. Cancer, 52, 1202-1209.

Wong, C.Y., Thie, J., Parling-Lynch, K.J., Zakalik, D., Margolis, J.H., Gaskill, M., Hill, J., Qing, F., Fink-Bennett, D. \& 
Nagle, C. (2005) Glucose-normalized standardized uptake value from (18)F-FDG PET in classifying lymphomas. The Journal of Nuclear Medicine, 46, 1659-1663.

Young, H., Baum, R., Cremerius, U., Herholz, K., Hoekstra, O., Lammertsma, A.A., Pruim, J. \& Price, P. (1999) Measurement of clinical and subclinical tumour response using [18F]-fluorodeoxyglucose and positron emission tomography: review and 1999 EORTC recommendations. European Organization for Research and Treatment of Cancer (EORTC) PET Study Group. European Journal of Cancer, 35, 1773-1782.

Zinzani, P.L., Fanti, S., Battista, G., Tani, M., Castellucci, P., Stefoni, V., Alinari, L., Farsad, M., Musuraca, G., Gabriele, A., Marchi, E., Nanni, C., Canini, R., Monetti, N. \& Baccarani, M. (2004) Predictive role of positron emission tomography (PET) in the outcome of lymphoma patients. British Journal of Cancer, 91,850-854. 
Table 1. Patients characteristics

\begin{tabular}{|c|c|c|c|c|c|}
\hline \multirow[t]{2}{*}{ Histology } & \multirow[t]{2}{*}{$\mathrm{N}^{\circ}$ of patients } & \multirow[t]{2}{*}{$\operatorname{Sex}(\mathbf{F} / M)$} & \multirow[t]{2}{*}{ Mean age, yrs (range) } & \multicolumn{2}{|c|}{$\begin{array}{c}\mathbf{N} \text { of Locations at PET-CT } \\
\text { (range) }\end{array}$} \\
\hline & & & & Extra-nodal & Nodal \\
\hline \multicolumn{6}{|l|}{ T-cell Lymphomas } \\
\hline MF & 3 & $0 / 3$ & $62(52-79)$ & $2-6$ & $4-5$ \\
\hline PTCL-U & 9 & $3 / 6$ & $56(20-76)$ & $1-7$ & $2-10$ \\
\hline ENKL & 1 & $1 / 0$ & 35 & 1 & 1 \\
\hline ALCL & 6 & $3 / 3$ & $49(21-68)$ & $1-1$ & $2-4$ \\
\hline AILT & 1 & $0 / 1$ & 53 & 0 & 6 \\
\hline \multicolumn{6}{|l|}{ Indolent B-NHL } \\
\hline FL & 18 & $6 / 12$ & $69(31-75)$ & $1-5$ & $1-14$ \\
\hline EMZL & 2 & $1 / 1$ & $51(45-58)$ & $1-2$ & 0 \\
\hline \multicolumn{6}{|l|}{ Aggressive B-NHL } \\
\hline DLBCL & 17 & $6 / 11$ & $61(51-78)$ & $1-2$ & - \\
\hline EMZL Blastic & 2 & $0 / 2$ & $48(21-75)$ & $1-1$ & - \\
\hline Intravascular LBCL & 1 & $0 / 1$ & 40 & 1 & - \\
\hline
\end{tabular}

MF, mycosis fungoides; PTCL-U, peripheral T-cell lymphoma unspecified; ENKL, extra-nodal natural killer/T-cell lymphoma, nasal type; ALCL, anaplastic large cell lymphoma; AILT, angioimmunoblastic T-cell lymphoma; NHL, nonHodgkin lymphoma; FL, follicular lymphoma; EMZL, extranodal marginal zone B-cell lymphoma; DLBCL, diffuse large B-cell lymphoma; LBCL, large B-cell lymphoma. 
Table 2. Characteristics of patients with TL at the time of FDG-PET scan

\begin{tabular}{|c|c|c|c|c|c|c|c|c|}
\hline $\begin{array}{l}\text { Pts } \\
\mathbf{N}^{\circ} \\
\end{array}$ & Sex & $\begin{array}{l}\text { Age } \\
\text { (yrs) }\end{array}$ & Histology & $\begin{array}{c}* \text { Locations } \\
\text { extranodal/nodal }\end{array}$ & $\begin{array}{l}{ }^{*} \text { CT lesion } \\
\text { size }(\mathrm{cm})\end{array}$ & $\begin{array}{c}\text { BM } \\
\text { biopsy }\end{array}$ & Stage & PET results \\
\hline 1 & $\mathrm{M}$ & 55 & $\mathrm{MF}$ & $\begin{array}{l}\text { subcutaneous in } \\
\text { chest/right axilla }\end{array}$ & $\begin{array}{l}2.1 \times 2.5 / \\
2.0 \times 2.6\end{array}$ & Neg. & IV & + \\
\hline 2 & M & 59 & PTCL-U & $\begin{array}{l}\text { left iliac region } \\
\text { (bone)/right inguinal }\end{array}$ & $\begin{array}{l}2.2 \times 2.4 / \\
2.3 \times 1.9\end{array}$ & Pos. & IV & + \\
\hline 3 & $\mathrm{~F}$ & 51 & ALCL & - /right iliac region & $1.8 \times 1.2$ & Pos. & IV & + \\
\hline 4 & $\mathrm{~F}$ & 20 & PTCL-U & C4 (bone)/ - & $2.8 \times 2.5$ & Pos. & IV & + \\
\hline 5 & M & 48 & ALCL & - /ant-sup mediastinum & $2.3 \times 2.0$ & Pos. & IVA & + \\
\hline 6 & $\mathrm{~F}$ & 38 & PTCL-U & mediastinal tissue/ - & $1.9 \times 2.9$ & Neg. & IIE & + \\
\hline 7 & $\mathrm{M}$ & 21 & ALCL & - /ant-sup mediastinum & $1.6 \times 2.7$ & Pos. & IV & + \\
\hline 8 & $\mathrm{~F}$ & 35 & ENKL & $\begin{array}{l}\text { posterior rino-farinx/right } \\
\text { submandibular }\end{array}$ & $\begin{array}{l}1.3 \times 1.4 / \\
1.2 \times 2.7\end{array}$ & Neg. & IIE & + \\
\hline 9 & M & 57 & PTCL-U & $\begin{array}{l}\text { right hepatic flexure } \\
\text { (colon)/ - }\end{array}$ & $1.9 \times 3.0$ & Pos. & IV & + \\
\hline 10 & M & 52 & MF & $\begin{array}{c}\text { left neck (skin)/bilateral } \\
\text { inguinal }\end{array}$ & $\begin{array}{l}1.1 \times 1.2 / \\
1.2 \times 1.4\end{array}$ & Neg. & IIIE & + \\
\hline 11 & M & 67 & PTCL-U & $\begin{array}{l}\text { posterior naso-farinx/right } \\
\text { iliac region }\end{array}$ & $\begin{array}{l}1.2 \times 2.0 / \\
2.3 \times 3.1\end{array}$ & Pos. & IV & + \\
\hline 12 & M & 79 & MF & $\begin{array}{c}\text { left neck (skin); } \\
\text { prostate/bilateral inguinal }\end{array}$ & $\begin{array}{l}1.2 \times 1.0 / \\
1.5 \times 2.7\end{array}$ & Neg. & IV & + \\
\hline 13 & M & 70 & PTCL-U & - / paratracheal & $1.7 \times 1.9$ & Neg. & IIB & + \\
\hline 14 & M & 53 & AITL & - /left iliac region & $1.3 \times 1.9$ & Pos. & IV & + \\
\hline 15 & $\mathrm{~F}$ & 46 & ALCL & - /ant-sup mediastinum & $1.7 \times 2.6$ & Neg. & III & + \\
\hline 16 & $\mathrm{~F}$ & 56 & PTCL-U & $\begin{array}{l}\text { acromion (bone)/ ant-sup } \\
\text { mediastinum }\end{array}$ & $\begin{array}{l}1.1 \times 1.5 / \\
1.5 \times 1.5\end{array}$ & Pos. & IV & + \\
\hline 17 & M & 62 & PTCL-U & gastric/paraortic & $\begin{array}{l}1.8 \times 3.1 / \\
1.3 \times 2.8\end{array}$ & Neg. & IV & + \\
\hline 18 & M & 76 & PTCL-U & - /left neck & $1.5 \times 2.5$ & Neg. & III & + \\
\hline 19 & $\mathrm{~F}$ & 68 & ALCL & $\begin{array}{l}\text { subcutaneous in leg /left } \\
\text { iliac region }\end{array}$ & $\begin{array}{l}1.6 \times 2.2 / \\
1.5 \times 1.6\end{array}$ & Pos. & IV & + \\
\hline 20 & M & 63 & ALCL & spleen/left neck & $\begin{array}{l}1.8 \times 2.5 / \\
1.2 \times 1.6\end{array}$ & Pos. & IV & + \\
\hline
\end{tabular}

MF, mycosis fungoides; PTCL-U, peripheral T-cell lymphoma unspecified; ENKL, extra-nodal natural killer/T-cell lymphoma, nasal type; ALCL, anaplastic large cell lymphoma; AILT, angioimmunoblastic T-cell lymphoma; *, most representative; BM, bone marrow; Pos., positive; Neg., negative 


\section{FIGURE LEGEND}

(Figure 1. Global maximum standardized uptake value in patients with $\mathbf{T}$ cell lymphoma and indolent or aggressive B-NHL. *, $p<0.001$ vs indolent $\mathrm{B}-\mathrm{NHL} ; \uparrow, \mathrm{p}<0.01$ vs aggressive $\mathrm{B}-\mathrm{NHL}$ )

(Figure 2.) Figure 1. Extra-nodal (A) and nodal (B) maximum standardized uptake value in patients with TL and indolent or aggressive B-NHL. ${ }^{*}, \mathrm{p}<0.05$ vs indolent $\mathrm{B}-\mathrm{NHL} ; \dagger, \mathrm{p}<0.01 \mathrm{vs}$ aggressive $\mathrm{B}-$ NHL

$15 \quad$ NHL




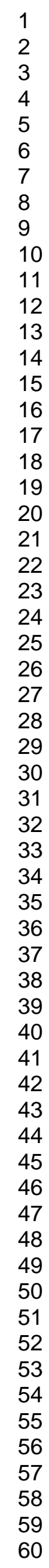
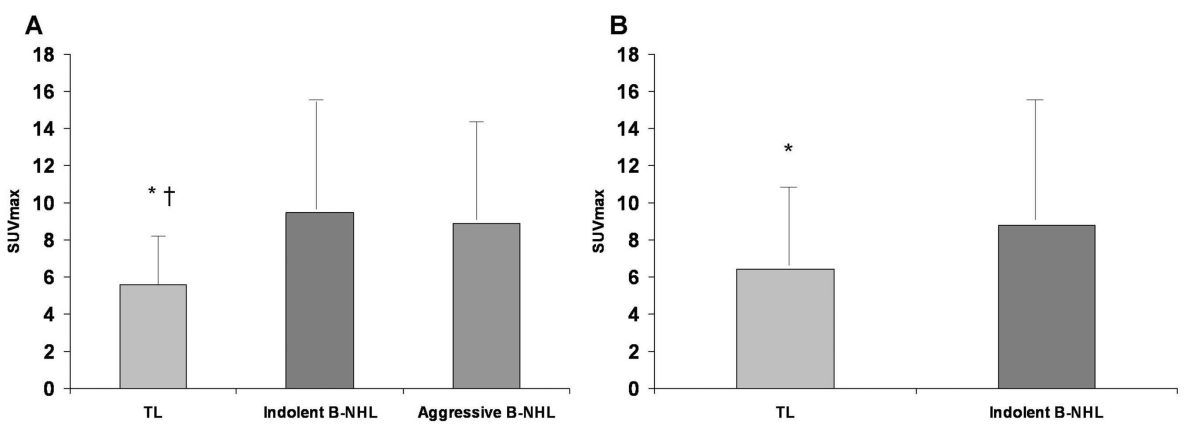

$127 \times 101 \mathrm{~mm}(600 \times 600 \mathrm{DPI})$ 